\title{
CONTROLE INTERNO E CONFLITOS DE INTERESSES EM INSTITUIÇÕES FINANCEIRAS ${ }^{1}$
}

\section{INTERNAL CONTROL AND CONFLICTS OF INTEREST IN FINANCIAL INSTITUTIONS}

\section{CONTROL INTERNO Y CONFLICTOS DE INTERÉS EN ENTIDADES FINANCIERAS}

Gustavo Henrique Costa Souza, Doutorando em Ciências Contábeis pela Universidade Federal de Pernambuco (UFPE). Endereço Profissional: Universidade Federal de Pernambuco, Av. Prof. Moraes Rego, 1235 - Cidade Universitária, Recife - PE, 50670-901, Telefone: (81) 2126-8000. E-mail: guga.hcs@gmail.com.

Elizâgela Borba Ferreira da Silva, Especialista pela Faculdade Frassinetti do Recife (FAFIRE). Endereço Profissional: Av. Conde da Boa Vista, 921 - Boa Vista, Recife - PE, 50060-002, Telefone: (81) 2122-3500. E-mail: elizangelaborba@ gmail.com.

Luiz Antônio Félix Júnior, Doutorando em Administração pela Universidade Potiguar (UnP). Endereço Profissional: Instituto Federal de Alagoas - Campus Benedito Bentes. Avenida Benedito Bentes (Cj Benedito Bentes II), Benedito Bentes, 57084649 -

Maceió, AL - Brasil, Telefone: (82) 2126-6230. URL da Homepage:

https://www2.ifal.edu.br/campus/site/campus_benedito. E-mail: juniorfelixx@ @otmail.com.

\section{RESUMO}

Ao definir as suas normas de controle interno, as organizações procuram estabelecer as regras e condutas que deverão orientar a relação comercial com seus clientes. Tais regras, em teoria, deveriam ser observadas e obedecidas pelos funcionários da instituição que as definiu a fim de assegurar a validade jurídica das transações efetivadas, garantir a clareza nos pactos firmados e evitar prejuízos de qualquer natureza. Diante do exposto, este trabalho teve por objetivo analisar se relações pessoais eventualmente mantidas entre funcionários e clientes das cinco maiores instituições financeiras do país provocam conflitos de interesses capazes de ocasionar o descumprimento destes normativos institucionais e expor a organização a toda sorte de riscos. Para isto, a estratégia metodológica definida foi a aplicação de questionário com os funcionários de dez sucursais bancárias situadas na Capital Pernambucana e também na Região Metropolitana de Recife. Os dados obtidos sugerem que o relacionamento pessoal entre clientes e funcionários das agências existe e, efetivamente, leva a estes últimos descumprirem aos controles internos, assumindo riscos que excedem os limites de tolerância determinados pela organização.

Palavras-chave: Controle interno; Conflitos de interesses; Instituições financeiras.

\section{ABSTRACT}

To define their internal control standards, organizations seek to establish the rules and conduct that should guide the business relationship with their customers. Such rules, in

\footnotetext{
${ }^{1}$ Artigo submetido em 02/04/2016, revisado em 24/04/2017, aceito em 20/06/2017 e divulgado em 10/07/2018 pelo Editor João Carlos Hipólito Bernardes do Nascimento, após double blind review.
} 
theory, should be observed and obeyed by employees of the institution which set in order to ensure the legal validity of the committed transactions, ensure clarity in signed agreements, and avoid losses of any nature. This study aimed to examine whether personal relationships eventually held between employees and customers of the five largest financial institutions in the country cause conflicts of interest capable of causing the failure of these institutional norms and expose the organization to all sorts of risks. For this, the defined methodological strategy was the application of questionnaire to employees ten bank branches. The data obtained suggest that there is, in fact, personal relationship between customers and employees of the agencies, and this effectively takes the latter disobey internal controls, taking risks that exceed the tolerance limits determined by the organization.

Keywords: Internal Control; Conflicts of Interest; Financial Institutions.

\section{RESUMEN}

Para definir sus normas de control interno, las organizaciones tratan de establecer las reglas y la conducta que deben guiar la relación comercial con sus clientes. Dichas normas, en teoría, deberían ser observadas y obedecidas por los empleados de la institución que las estableció con el fin de asegurar la validez jurídica de las operaciones realizadas, garantizar la claridad en los acuerdos firmados, y evitar las pérdidas de cualquier naturaleza. Este estudio tuvo como objetivo examinar si las relaciones personales entre los empleados y clientes de las cinco instituciones financieras más grandes del país causan conflictos de interés que puedan causar el fracaso de estas normas institucionales y exponer a la organización a todo tipo de riesgos. Para eso, la estrategia metodológica definida fue la aplicación de un cuestionario a los empleados de diez sucursales bancarias. Los datos sugieren que, de facto, hay una relación personal entre los clientes y los empleados de las agencias, y que esta relación hace con que no se sigan los controles internos y, consecuentemente, sean asumidos riesgos que exceden los límites de tolerancia determinados por la organización.

Palabras clave: Control Interno; Conflictos de interés; Instituciones financieras.

\section{INTRODUÇÃO}

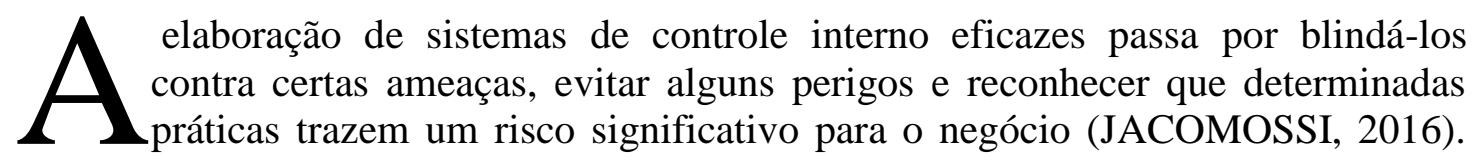
Entretanto, idealizar e implementar um sistema de controle interno com esta consciência não garante, necessariamente, o seu funcionamento e sucesso. As estruturas de controle dependem das pessoas que as coordenam, mantém e operam. Da mesma forma, os "padrões" de controle só serão realmente seguidos se as pessoas encarregadas do seu cumprimento tiverem interesse em adotá-los, e se os gestores estiverem cônscios do seu papel de guardiães da norma (ANTHONY; GOVINDARAJAN, 2001)

Contudo, havendo incongruência entre os interesses de patrões e empregados, entra em cena o elemento risco, que - no âmbito das instituições do ramo financeiro - pode ocasionar prejuízos financeiros significativos, além de apresentar várias motivações e assumir diferentes contornos. Em algumas situações, o conflito de interesses pode ter origem em conflitos de ordem ética, quando as relações interpessoais motivarem a realização de negócios desvantajosos, mas também pode ter implicações positivas, quando tais relações ajudarem a suavizar a resistência do cliente no fechamento de uma operação.

Para capturar tais situações conflitantes, foi necessário abordar funcionários de agências bancárias interrogando-os sobre sua relação com os clientes e suas atividades rotineiras. Assim, elaborou-se um questionário cujas perguntas ora requeriam do respondente 
a emissão de um juízo particular sobre uma situação específica (com potencial de exposição a riscos), ora tratavam de procedimentos que permeiam o dia a dia de um bancário,

Diante do exposto, esta pesquisa pretende oferecer uma dupla contribuição: em primeiro lugar, intenta colaborar com o arcabouço de conhecimentos teóricos desenvolvidos pela academia acerca das particularidades dos sistemas de controle interno em instituições financeiras; além disto, este estudo almeja estimular as instituições financeiras a aprimorarem seus instrumentos de controle a fim de possibilitar maior grau de prevenção de riscos associados ao descumprimento de normas. Dada a representatividade que o segmento bancário tem para o mercado brasileiro, e considerando que não foram identificados estudos brasileiros com a abordagem aqui descrita, este trabalho assume uma característica diferencial que justifica a sua realização.

A pesquisa então, emerge da seguinte questão problema: o relacionamento interpessoal entre clientes e funcionários de instituições financeiras ocasiona desobediência às normas de controle interno? Partindo deste questionamento o presente trabalho objetivou verificar se o relacionamento interpessoal entre clientes e funcionários de instituições financeiras motiva o descumprimento de normas institucionais.

Além dessa parte introdutória, que contextualiza o tema e define o propósito da pesquisa, o presente estudo contempla: o referencial teórico sobre o tema, incluindo uma discussão sobre compliance e riscos no setor bancário e conflitos de interesse; a descrição da metodologia da pesquisa; a análise dos dados e discussão; as considerações finais e por fim as referências do estudo

\section{REFERENCIAL TEÓRICO}

\subsection{COMPLIANCE E RISCOS NO SETOR BANCÁRIO}

Ao estudar a implementação de regras de compliance em bancos italianos, Birindelli e Ferretti (2013) demonstraram uma associação entre risco operacional e risco de compliance. Assim, o trabalho de Birindelli e Ferreti (2013) chama a atenção para a relação entre falhas operacionais e regras de comportamento, bem como para a inserção de elementos éticos e de conduta nas diretrizes de controle das organizações bancárias. O grau de adesão das pessoas de uma instituição às normas de controle interno que tratam de conflitos de interesses e de outros dilemas éticos revela o quanto estas pessoas estão afinadas e comprometidas com o modelo organizacional.

Laruccia e Yamada (2013) afirmam que o papel da gestão do compliance dentro das instituições financeiras é importante para mitigar diversos tipos de risco - entre os quais destacam o ambiental, o de imagem e o financeiro (que, em geral, se materializa pela inadimplência). Lima e Lopes (1999) alertam para outro tipo de risco, o operacional, e o associa a problemas de ordem tecnológica e à capacidade de processamento de informações. Deloach (2001), com uma visão mais ampla, ao falar deste tipo de risco faz referência à ineficácia e ineficiência na execução do modelo de negócio da empresa - e não apenas à insuficiência tecnológica e comunicacional que havia sido sinalizada por Lima e Lopes (1999).

No contexto das empresas do ramo financeiro, Gitman (1997, p. 202) traça claramente a ligação entre risco e finanças ao afirmar que risco é "a possibilidade de prejuízo financeiro". O autor afirma ainda que "o termo risco é usado alternativamente com incerteza, ao referir-se à variabilidade de retornos associada a um dado ativo". Com esta afirmação, ele sinaliza que a fragilidade dos controles internos de uma organização pode ocasionar riscos que, em última instância, impactarão no resultado financeiro da companhia (e, por conseguinte, ameaçarão a sua capacidade de dar retorno aos seus acionistas). O intercâmbio de boas práticas de 
controle, por outro lado, produz o efeito contrário: ajuda a consolidar padrões de qualidade que direcionam a avaliação dos processos e que, ao fim, também refletirão nos resultados da empresa (MARSHALL, 2002).

\subsection{CONFLITOS DE INTERESSES}

Bouças e Gomes (2010) alertam que o atingimento dos objetivos da organização resulta de uma combinação, de um alinhamento, entre os interesses da empresa e os interesses individuais de cada membro da organização. Nesta mesma linha de pensamento, Léliz e Mario (2009, p. 3) indicam que o "desalinhamento de interesses [...] inibe a otimização dos recursos e a maximização dos retornos da firma".

Léliz e Mário (2009) colocam ainda que a redução desta incongruência entre os interesses poderia aumentar a riqueza da organização. Ao traçar a ligação entre os conflitos de interesses e os retornos esperados, os autores afirmam que a minimização destes conflitos é uma tentativa de fazer com que os riscos não se materializem e prejudiquem a empresa.

O hiato entre os objetivos das pessoas e os das organizações foi estudado Jensen e Meckling (1976) quando preconizaram a chamada Teoria da Agência. Os autores estabeleceram que quando em uma organização o dono do capital (chamado "principal") e as pessoas que para ele trabalham (chamados "agentes") têm interesses destoantes, está configurado o chamado "conflito de agência". Para gerenciar tal conflito o principal costuma empregar recursos financeiros e sistemas de controle. Sobre este último ponto, convém destacar que Merchant e Simons (1986) realizaram um robusto estudo sobre as noções de controle e gestão à luz da Teoria da Agência (e também da psicologia)

A relação entre patrões e empregados é mediada por contratos (tácitos ou escritos) que vão nortear o comportamento dos indivíduos dentro da organização. Neste sentido, Léliz e Mario (2009, p. 3) incluem entre as formas de monitoramento dos funcionários as "estruturas formais de controle interno" e pontuam que "o comportamento individual nas organizações [...] depende da natureza dos contratos firmados dentro do ambiente da firma". Gerir tais contratos é uma importante ferramenta de controle.

A Figura 1 expressa como se origina o impacto em controles internos de que trata o presente estudo.

Figura 1 - Fluxo Explicativo do Impacto em Controles Internos

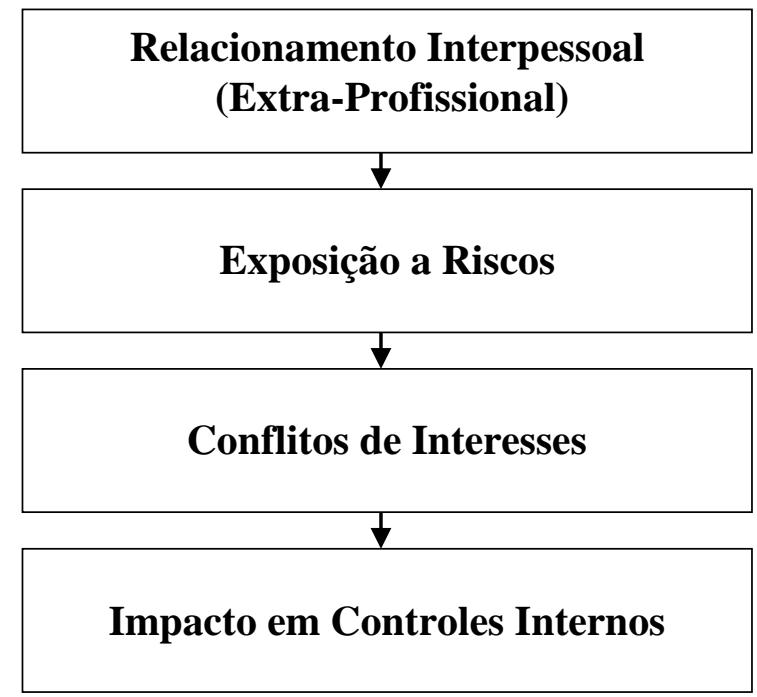

Fonte: elaborado pelos autores, com base nos dados da pesquisa. 
A existência de relacionamentos próximos, ou mesmo íntimos, entre funcionários e clientes, cuja motivação excede as razões de cunho comercial, constitui uma ligação não profissional (ou extraprofissional) arriscada. O patrão - que procura não expor desnecessariamente a empresa a riscos - corre o perigo de que seus funcionários, em razão da amizade construída com clientes, extrapolem os limites de risco que estão autorizados a correr. Em outras palavras: o interesse do patrão será minimizar o risco, ao passo que o interesse dos funcionários estará em preservar os laços particulares que estabeleceram. Está caracterizado aí o conflito de interesses que, uma vez instaurado, pode impactar a implementação dos controles internos bem como o cumprimento das normas da organização. A natureza deste impacto, se prejudicial ou benéfica, será desvendada e discutida no presente estudo na fase de análise dos dados coletados.

Isto posto, emerge da reflexão teórica apresentada, a seguinte hipóteses de pesquisa:

HO: O relacionamento interpessoal entre clientes e funcionários gera conflitos de interesses que afetam a implementação e o cumprimento das normas de controle interno.

A hipótese H0, por sua própria natureza e formulação, demanda a construção de uma linha de raciocínio especialmente clara, capaz de levar à aceitação ou rejeição da hipótese com segurança e sem viés. Para tanto, antes de ser testada, a hipótese H0 precisou passar pelo crivo de algumas questões preliminares, quais sejam: há indícios de relacionamento pessoal (não profissional) entre clientes e funcionários? (P1); há conflitos de interesses que expõem a instituição a riscos não desejados pelo principal? (P2); os funcionários toleram riscos não desejados pelo principal em razão de ligações particulares com clientes? (P3). Estas questões preliminares estão intimamente conectadas e devem ser verificadas na ordem apresentada para que a referida hipótese faça sentido. $\mathrm{O}$ procedimento que será seguido a partir das respostas obtidas está indicado a seguir, no Quadro 1:

Quadro 1 - Matriz de Análise da Hipótese Ho

\begin{tabular}{|c|c|c|}
\hline Questões Preliminares & Resposta & Procedimento \\
\hline \multirow{2}{*}{$\begin{array}{l}\text { P1: Há indícios de relacionamento pessoal (não profissional) } \\
\text { entre clientes e funcionários? }\end{array}$} & Sim & Prosseguir para Premissa P2 \\
\hline & Não & Rejeitar hipótese $\mathrm{H} 0$ \\
\hline \multirow{2}{*}{$\begin{array}{l}\text { P2: Há conflitos de agência que expõem a instituição } \\
\text { a riscos não desejados pelo patrão? }\end{array}$} & Sim & Prosseguir para Premissa P3 \\
\hline & Não & Rejeitar hipótese $\mathrm{H} 0$ \\
\hline \multirow{2}{*}{$\begin{array}{l}\text { P3: Os funcionários toleram riscos não desejados pelo patrão } \\
\text { em razão de ligações particulares com clientes? }\end{array}$} & Sim & Aceitar hipótese H0 \\
\hline & Não & Rejeitar hipótese H0 \\
\hline
\end{tabular}

Fonte: elaborado pelos autores, com base nos dados da pesquisa.

\section{METODOLOGIA}

Quanto aos objetivos, a pesquisa pode ser classificada como exploratória; e quantos aos procedimentos, trata-se de um levantamento. O estudo tem, ainda, a característica de pesquisa pura (isto é: não aplicada), tendo em vista que visa o progresso do conhecimento científico em si, não se prestando a implementar ou testar nenhum modelo já desenvolvido em outras pesquisas.

\subsection{AMOSTRA}

Esta pesquisa elegeu as empresas do setor financeiro como seu campo particular de estudo. O critério de escolha dos sujeitos de pesquisa levou em consideração a representatividade da carteira destas instituições. Admitiu-se que quanto maior o volume de depósitos que elas recebem, maior a confiança que elas inspiram, maior a responsabilidade 
sobre tais recursos, e - consequentemente - mais consistentes devem ser os controles internos que orientam o manejo destes recursos.

Assim, tendo em vista as restrições de recursos para um universo de estudo mais amplo, foram escolhidas duas agências de cada uma das cinco maiores instituições financeiras (bancárias) do país, em termos de depósito total. O ranking que contém esta informação é divulgado mensalmente no site do banco central (www.bcb.gov.br). As agências foram determinadas por critérios de conveniência e acessibilidade, sendo que - obrigatoriamente uma deveria estar situada na Capital Pernambucana e outra na Região Metropolitana de Recife.

É preciso deixar claro que não fizeram parte desta amostra sucursais com atendimento diferenciado para o público de alta renda. Isto porque os controles internos nestas sucursais já são, institucionalmente, flexibilizados - em vista das necessidades específicas da carteira de clientes delas.

\subsection{TÉCNICA DE INVESTIGAÇÃO}

A técnica escolhida para realização da pesquisa foi a da aplicação de questionários, os quais foram distribuídos, respondidos e recolhidos de forma eletrônica através do site Survey Monkey. $\mathrm{O}$ acesso aos funcionários das sucursais foi negociado mediante visita e conversa com o gestor da unidade. Foi garantida a todos os respondentes a preservação de suas identidades, a confidencialidade das suas respostas, e o respeito ao princípio voluntarismo que é um requisito de ordem ética adotado no Brasil.

Foram respondentes do questionário funcionários da área operacional das sucursais (tais como caixas, supervisores e tesoureiros), e funcionários da área comercial (tais como assistentes comerciais, gerentes de relacionamento e gerentes gerais).

O questionário foi dividido em três partes: a primeira visou identificar o perfil do respondente; a segunda constou de perguntas objetivas diretas - as quais foram respondidas monossilabicamente com "sim" ou "não"; por fim, a terceira parte trouxe um conjunto de questões de caráter subjetivo, que foram valoradas de acordo com a Escala Likert de cinco pontos (discordo totalmente, discordo parcialmente, não concordo nem discordo, concordo parcialmente, concordo totalmente). Os dados foram tabulados com o auxílio do software Microsoft Excel ${ }^{\circledR}$, versão 2007.

\section{ANÁLISE DOS DADOS E DISCUSSÃO}

\subsection{PERFIL DOS RESPONDENTES}

Com relação ao perfil dos respondentes é importante destacar que $60 \%$ deles têm entre 25 e 35 anos e $62 \%$ são mulheres. Embora $40 \%$ dos respondentes informe que trabalha na instituição em que está há menos de cinco anos, quase a metade deles (48\%) já exerce função gerencial. 92\% das pessoas que responderam à pesquisa residem em Recife.

\subsection{INDÍCIOS DE RELACIONAMENTO PESSOAL}

A seção que se segue, cujos dados são apresentados de modo condensado nas Tabelas 1 a 6 , é o resultado de uma investigação conduzida no sentido de identificar possíveis indícios de relacionamento pessoal entre os clientes e os funcionários das agências bancárias em análise.

A Tabela 1 trata da existência de parentesco entre os funcionários e os clientes. $38,78 \%$ dos respondentes disseram não ter familiares com conta na agência em que trabalham. 
Porém, a maior parte - representada por $59,18 \%$ - admitiram ter parentes como clientes da agência em que estão lotados.

Tabela 1 - Tem parente(s) com conta nesta agência?

\begin{tabular}{lcc}
\hline & Frequência Relativa & Frequência Absoluta (\%) \\
\hline Sim & 29 & 59,18 \\
\hline Não & 19 & 38,78 \\
\hline Não se aplica às funções desempenhadas & 1 & 2,04 \\
\hline Total & 49 & 100 \\
\hline
\end{tabular}

Fonte: elaborado pelos autores, com base nos dados da pesquisa.

Alguns esclarecimentos merecem ser feitos a respeito deste tópico. O primeiro deles concerne ao fato de que a pergunta feita não levou em consideração o tipo de conta que o parente do funcionário teria. Para o escopo deste estudo, não interessa diferenciar o cliente que possui conta corrente daquele que possui conta poupança, por exemplo. A questão apresentada aos respondentes visa apenas identificar a existência de um relacionamento, de um vínculo, entre a rede familiar do bancário e o seu local de trabalho, sendo este relacionamento expresso por meio de uma conta - qualquer que seja a natureza da mesma.

Outro esclarecimento que merece ser feito diz respeito ao fato de que, ao inquirir o bancário sobre se ele (a) tem parentes com conta na agência em que atuam, não importa saber se eles foram ou são os responsáveis diretos pela abertura ou manutenção de tais contas.

Embora não se possa dizer com certeza que o simples fato de possuir uma conta na agência em que se tem um parente trabalhando (ou: trabalhar em uma unidade onde um parente mantém conta) gera favorecimentos, facilitações, ou qualquer tipo de confusão entre a dimensão pessoal e a profissional, pode-se dizer que tal situação, no mínimo, cria possibilidades e oferece as condições para que tais coisas ocorram (e, portanto, representa um indício de relacionamento pessoal).

Quanto a possuir amigos com conta na agência, como exposto na Tabela 2, verificouse semelhante resultado e, por conseguinte, entendimento similar. $67,35 \%$ dos respondentes registraram possuir amigo com contas nas suas agências.

Tabela 2 - Tem amigo(s) com conta nesta agência?

\begin{tabular}{lcc}
\hline & Frequência Relativa & Frequência Absoluta (\%) \\
\hline Sim & 33 & 67,35 \\
\hline Não & 15 & 30,61 \\
\hline Não se aplica às funções desempenhadas & 1 & 2,04 \\
\hline Total & 49 & 100 \\
\hline
\end{tabular}

Fonte: elaborado pelos autores, com base nos dados da pesquisa.

É preciso ter em mente que tanto os vínculos de amizade quanto os de parentesco propiciam o mesmo risco para a instituição bancária. Na presente pesquisa, portanto, a distinção entre parentes e amigos decorre de razões meramente didáticas: visa auxiliar aos respondentes a se recordar mais claramente das pessoas com quem mantém algum tipo de relação pessoal (seja por pertencer à mesma parentela, seja por pertencer ao mesmo círculo de amizades).

Apesar da grande parte dos respondentes ter relatado que tem familiares e amigos como clientes de suas respectivas agências, como demonstrado das Tabelas 1 e 2, 71,4\% afirmou não encontrar-se com clientes fora do ambiente de trabalho. É o que demonstra a Tabela 3, abaixo: 
Tabela 3 - Encontra-se com cliente(s) fora do ambiente da agência?

\begin{tabular}{lcc}
\hline & Frequência Relativa & Frequência Absoluta (\%) \\
\hline Sim & 13 & 26,5 \\
\hline Não & 35 & 71,4 \\
\hline Não se aplica às funções desempenhadas & 1 & 2,0 \\
\hline Total & 49 & 100,0 \\
\hline
\end{tabular}

Fonte: elaborado pelos autores, com base nos dados da pesquisa.

Vale salientar que embora em um primeiro momento este dado possa causar estranheza, não se pode perder de vista que a sociedade do século XXI, com tantas ferramentas tecnológicas à sua disposição, passa por um momento de virtualização das relações humanas. De modo que não é incompatível ter amigos e parentes como clientes e, mesmo assim, não encontrar-se com eles.

$\mathrm{Na}$ Tabela 4, pode-se observar que a temática das conversas entre funcionários e clientes nem sempre se atém a assuntos estritamente ligados à prestação de serviços financeiros (englobada nesta prestação a oferta de produtos). 77,6\% dos respondentes da pesquisa relataram que tratam, sim, de assuntos paralelos ao trato negocial com os clientes.

Tabela 4 - Conversa com cliente(s) sobre assuntos alheios à prestação de serviços financeiros?

\begin{tabular}{lcc}
\hline & Frequência Relativa & Frequência Absoluta (\%) \\
\hline Sim & 38 & 77,6 \\
\hline Não & 11 & 22,4 \\
\hline Não se aplica às funções desempenhadas & 0 & 0,0 \\
\hline Total & 49 & 100,0 \\
\hline
\end{tabular}

Fonte: elaborado pelos autores, com base nos dados da pesquisa.

A priori isto não indica que necessariamente haja conversas de cunho íntimo entre clientes e funcionários. Isto porque o processo de venda de qualquer produto ou serviço (ligado à atividade financeira ou não) requer a sondagem de algumas informações para que o vendedor (neste caso, o bancário) possa fazer uma oferta adequada e convença o cliente a fechar uma operação. Contudo, não se pode negar que nestas ocasiões se abre uma "brecha", uma oportunidade, para que o diálogo se acentue e favoreça o processo de construção de um relacionamento pessoal. Por isso, está-se admitindo na presente pesquisa que a conversa sobre assuntos alheios ao trato negocial constitui um indício (embora não uma certeza) de relacionamento pessoal entre clientes e funcionários das sucursais bancárias investigadas.

A seguir, a Tabela 5 traz um diferencial na análise feita até então: ela indaga acerca do comportamento dos colegas dos respondentes. Das 49 pessoas arguidas, 37 afirmaram ter "algum colega (também bancário) que tinha ligações pessoais com cliente(s) da agência em que atuava". Isto significa, como mostra a tabela abaixo, que $75,5 \%$ dos respondentes já testemunhou tal fato.

Tabela 5 - Já soube de algum colega (também bancário) que tinha ligações pessoais com cliente(s) da agência em que atuava?

\begin{tabular}{lcc}
\hline & Frequência Relativa & Frequência Absoluta (\%) \\
\hline Sim & 37 & 75,5 \\
\hline Não & 12 & 24,5 \\
\hline Não se aplica às funções desempenhadas & 0 & 0,0 \\
\hline Total & 49 & 100,0 \\
\hline
\end{tabular}

Fonte: elaborado pelos autores, com base nos dados da pesquisa.

Ao mesmo temo em que esta questão visa, por outro prisma, verificar a ocorrência destas conexões particulares entre clientes e funcionários, ela também testa o grau de coerência e veracidade entre as respostas dos bancários. Diante dos indícios apontados nas 
questões/tabelas anteriores, seria algo inusitado se os respondentes não apontassem a existência concreta destas ligações pessoais.

Naturalmente, não foi requerido que os bancários dessem uma resposta em primeira pessoa acerca desta matéria porque se supõe que - seja por conservadorismo moral, seja por prudência em relação às desconhecidas consequências de suas respostas - eles teriam dificuldades em admitir as suas próprias ligações pessoais com clientes da agência. Isto, em última análise, provocaria distorções e vieses, comprometendo os resultados da pesquisa. Assim, a estratégia de perguntar sobre as ligações de terceiros (seus colegas de trabalho) livrou este viés e permitiu a obtenção de um resultado consoante com os indícios anteriormente apresentados.

Quando questionados sobre o cumprimento de metas e a utilização de seus clientes mais próximos para tal fim, avaliou-se - conforme mostra a Tabela 6 - que $83,7 \%$ dos entrevistados disseram realizar a prática de entrar em contato com estes clientes para requisitar-lhes apoio com vistas ao atingimento dos objetivos estabelecidos pela empresa.

Tabela 6 - Para atingir metas, já entrou em contato com cliente(s) mais próximos a fim de solicitar apoio dos mesmos para cumprir certos objetivos?

\begin{tabular}{lcc}
\hline & Frequência Relativa & Frequência Absoluta (\%) \\
\hline Sim & 41 & 83,7 \\
\hline Não & 7 & 14,3 \\
\hline Não se aplica às funções desempenhadas & 1 & 2,0 \\
\hline Total & 49 & 100,0 \\
\hline
\end{tabular}

Fonte: elaborado pelos autores, com base nos dados da pesquisa.

Sobre este ponto é importante comentar duas coisas: a primeira diz respeito ao termo "clientes mais próximos". Ao responder positivamente a uma questão escrita nestes termos, os respondentes estão não só confessando uma prática, mas também - ao mesmo tempo admitindo que existem, sim, clientes com os quais eles têm um nível de proximidade maior. Este é, portanto, um flagrante que corrobora o resultado obtido na questão anterior (vide Tabela 6). Tomadas em conjunto, as questões 5 e 6 sinalizam que, tanto os respondentes quanto os seus colegas de trabalho, possuem - sim - ligações particulares com clientes. E estas ligações são de tal modo estreitas que os bancários chegam ao ponto, inclusive, de acionar estes clientes mais próximos para que eles (mais por solidariedade que por necessidade) ajudem a cumprir suas metas mediante aquisição dos produtos e/ou serviços financeiros.

A outra coisa que merece ser comentada diz respeito à motivação dos bancários quando contatam estes clientes ditos "mais próximos". Não é objeto da presente pesquisa a análise de motivações pessoais. Não se quer aqui conjecturar sobre o que leva um bancário a agir deste ou daquele modo. Contudo, não se pode ignorar a observação de Silva e Navarro (2012, p. 227-228):

Os bancários passaram por momentos de redefinição em seus "traços constitutivos", transformaram-se em "bancários-vendedores", capacitados para atender integralmente os seus clientes, muitas vezes de forma individualizada, para cumprir metas a eles impostas de vendas de títulos, seguros, aplicações e demais produtos e serviços bancários (SILVA; NAVARRO, 2012, p. 227-228)

Em outras palavras: a transformação do bancário em um vendedor (constantemente pressionado a atingir metas de venda) pode estar na raiz de algumas práticas. $\mathrm{O}$ 'bancáriovendedor' - premido pela necessidade de satisfazer seu patrão e, assim, manter-se empregado - acaba se valendo de pessoas próximas (neste caso, clientes) que lhes possam ajudar neste sentido. 
Assim, chegando ao fim da seção 4.2, pode-se concluir - a partir dos dados obtidos que há sim indícios de relacionamento pessoal entre os clientes e funcionários das agências bancárias que participaram desta pesquisa e, portanto, está validada a premissa P1 ("Há indícios de relacionamento pessoal (não profissional) entre clientes e funcionários?"). Retomando a estratégia de prova anteriormente definida, uma vez ratificada a premissa P1, a fase seguinte deve ser a análise dos riscos. Deste modo, na seção 4.3, seguinte, pretende-se validar (ou não) a premissa P2, a qual argui: "Há conflitos de agência que expõem a instituição a riscos não desejados pelo patrão?”.

\subsection{EXPOSIÇÃO A RISCOS DECORRENTES DE CONFLITOS DE INTERESSES}

Nesta etapa, foram feitos questionamentos no sentido de identificar conflitos de interesse capazes de colocar a figura do banco em risco. $\mathrm{O}$ primeiro procedimento sobre o qual os respondentes foram indagados foi o da coleta de assinatura.

Como indicado na Tabela $7,75 \%$ dos entrevistados declararam já ter realizado o procedimento de coleta de assinatura em data posterior a da efetivação da operação.

Tabela 7 - Já colheu assinatura posteriormente à realização de operação?

\begin{tabular}{lcc}
\hline & Frequência Relativa & Frequência Absoluta (\%) \\
\hline Sim & 36 & 75,0 \\
\hline Não & 11 & 22,9 \\
\hline Não se aplica às funções desempenhadas & 1 & 2,1 \\
\hline Total & 48 & 100,0 \\
\hline
\end{tabular}

Fonte: elaborado pelos autores, com base nos dados da pesquisa.

A situação exposta na tabela acima constitui uma confissão expressiva e importante no que diz respeito à temática "riscos". A aposição de assinatura ex post facto representa uma lacuna na formalização do negócio, o que - juridicamente - pode ensejar a nulidade ou o desfazimento da operação.

Contudo, a existência - anteriormente comprovada - de relações pessoais entre bancários e clientes faz com que o procedimento de coleta de assinatura seja deixado para 'depois'. Seja por confiar no cliente, seja pela pressa em fechar negócio (e, assim, cumprir metas), o fato é que esta atitude conflita com os interesses do banqueiro - que quer cumprir as exigências formalísticas a fim de preservar seu patrimônio, evitando desgastes judiciais e prejuízos financeiros decorrentes de transações feitas sem o trato jurídico adequado.

Apesar de "burlar" a questão da assinatura 50\% dos respondentes afirma não dispensam procedimentos padrão exigidos pelas entidades bancárias. Em um primeiro momento este resultado induz o pesquisador a suspeitar de incoerência nas respostas: se $75 \%$ dos respondentes já colheram assinatura posteriormente à formalização do negócio, então - no mínimo - estes mesmos $75 \%$ deveriam ter admitido que já dispensaram procedimentos obrigatórios. Na Tabela 8, os resultados, a priori controversos, podem ser visualizados melhor:

Tabela 8 - Já dispensou procedimento padrão exigido pela organização por julgar que a operação era corriqueira e recorrente?

\begin{tabular}{lcc}
\hline & Frequência Relativa & Frequência Absoluta (\%) \\
\hline Sim & 22 & 45,8 \\
\hline Não & 24 & 50,0 \\
\hline Não se aplica às funções desempenhadas & 2 & 4,2 \\
\hline Total & 48 & 100,0 \\
\hline
\end{tabular}

Fonte: elaborado pelos autores, com base nos dados da pesquisa. 
Contudo, esta diferença pode ser explicada de dois modos: primeiro, alguns podem ter respondido a questão 8 de forma negativa porque a dispensa de procedimento que perpetraram não foi motivada "por julgar que a operação era corriqueira e recorrente". Dispensaram por outras razões, que não esta. Segundo: a resposta "não" ao nono quesito pode indicar que - em alguns casos - a aposição de assinatura não é "procedimento padrão exigido pela organização". Logo, colhê-la a posteriori não significa, necessariamente, ter dispensado "procedimento padrão". Esta última interpretação, embora difícil de exemplificar no plano dos eventos, parece possível e plausível no plano das hipóteses.

A justificativa para tal dispensa de procedimento (confessada por $45,8 \%$ dos respondentes) encontra-se na própria formulação da questão: "por julgar que a operação era corriqueira e recorrente". O caso, e o problema, é que este mitigador de riscos inexiste na norma das organizações e não é, de modo algum, autorizado pelo banqueiro. $O$ fato de a operação ter caráter 'corriqueiro' (trivial, banal) não indica que ela esteja livre de riscos ou que estes sejam tão pequenos que possam ser desconsiderados; da mesma forma, a operação julgada recorrente (costumeira, habitual) não está imune a fraudes e engodos perigosos. Portanto, está-se diante de um caso em que o funcionário cria uma 'norma paralela', estabelecendo exceções à norma institucional e concedendo autorizações a si mesmo, à revelia do que recomendam os controles internos - que materializam os interesses do patrão e a forma como ele deseja que os negócios sejam conduzidos.

Passando à décima questão, a realidade que se constata ganha novos e diferentes contornos: como mostra a Tabela 9, 68,8\% dos respondentes afirmam que não se valem de alçadas superiores para abonar operações fora do padrão.

\section{Tabela 9 - Costuma acionar e utilizar alçadas superiores para abonar operações fora do padrão?}

\begin{tabular}{lcc}
\hline & Frequência Relativa & Frequência Absoluta (\%) \\
\hline Sim & 12 & 25,0 \\
\hline Não & 33 & 68,8 \\
\hline Não se aplica às funções desempenhadas & 3 & 6,3 \\
\hline Total & 48 & 100,0 \\
\hline
\end{tabular}

Fonte: elaborado pelos autores, com base nos dados da pesquisa.

Múltiplas interpretações decorrem deste resultado. Primeiramente, como demonstrado na Tabela 1, 48\% dos entrevistados são gerentes - o que, naturalmente, lhes dá mais autonomia para decidir e operar. Portanto, era esperado que a maior parte dos respondentes não precisasse recorrer a outras instâncias para requerer certas autorizações. Depois, é possível que, em alguns casos, a utilização de alçadas superiores gere desconforto ou até advertência. Pedir que um gerente geral ou superintendente, por exemplo, abone uma operação que claramente foge aos padrões pode levar a questionamentos sobre as opções éticas do subalterno solicitante resultando, inclusive, na aplicação de medidas disciplinares contra ele. Assim, é compreensível que a maioria dos respondentes não faça este tipo de acionamento.

Contudo, 25\% dos respondentes admitiram "acionar e utilizar alçadas superiores para abonar operações fora do padrão". Tal comportamento, embora represente um compartilhamento ou mesmo uma transferência da culpa inerente à transgressão da norma, revela um claro desacordo em relação aos interesses do banqueiro (que estabeleceu o "padrão" a fim de protegê-los). Naturalmente, esta divergência gera exposição a riscos.

Neste ponto do trabalho, é possível afirmar que há, sim, "conflitos de agência que expõem a instituição a riscos não desejados pelo patrão (premissa P2)". Os dados obtidos a partir das respostas às questões 7,8 e 9 credenciam a que tal afirmação seja feita. Portanto, seguindo o procedimento de prova anteriormente traçado, é preciso - agora - investigar se 
estes conflitos de interesses, e os riscos a eles inerentes, estão associados a "ligações particulares com clientes" (premissa P3). Isto será feito a partir das provocações trazidas pelas questões 10 e 11, apresentadas a seguir.

$\mathrm{Na}$ Tabela 10 percebe-se que os respondentes dividem-se quanto ao recebimento de presentes em datas comemorativas. 54,2\% afirmam receber de clientes tais mimos, e 43,8\% dizem não receber.

Tabela 10 - Em datas comemorativas (Páscoa, Natal, Festas Juninas, etc.) costuma receber presente(s) do(s) mesmo(s) cliente(s)?

\begin{tabular}{lcc}
\hline & Frequência Relativa & Frequência Absoluta (\%) \\
\hline Sim & 26 & 54,2 \\
\hline Não & 21 & 43,8 \\
\hline Não se aplica às funções desempenhadas & 1 & 2,1 \\
\hline Total & 48 & 100,0 \\
\hline
\end{tabular}

Fonte: elaborado pelos autores, com base nos dados da pesquisa.

Antes de analisar estas respostas convém esclarecer a formulação da pergunta: é próprio da cultura brasileira receber (ou mesmo trocar) presentes em datas comemorativas. Contudo, o diferencial desta questão está em quem oferece o presente: "o(s) mesmo(s) cliente(s)". O fato de não ser um cliente qualquer oferecendo um regalo em uma situação pontual aponta para a criação de um costume baseado em um vínculo: trata-se do mesmo funcionário recebendo presente do mesmo cliente em uma mesma ocasião.

Portanto, a aceitação costumeira de presentes dados pelos mesmos clientes a funcionários de agências bancárias constitui um perigo para o negócio e um evidente conflito de interesses: o funcionário quer preservar os laços que criou com o cliente enquanto que o banqueiro quer preservar seu patrimônio.

Seguindo a mesma lógica da Tabela 5, abaixo, a questão apresentada na Tabela 11 insere uma arguição sobre o comportamento alheio. Como dito anteriormente, esta estratégia de investigação é utilizada no presente estudo com a finalidade de evitar que, por escrúpulo de serem descobertos e julgados os participantes do estudo não fossem sinceros em suas respostas. Apesar de o pesquisador lhes ter dado, conforme protocolo ético, a garantia de confidencialidade das respostas, poderia ocorrer de alguém não se sentir à vontade de responder com veracidade um questionamento tão contundente. Ao perguntar sobre o comportamento de um terceiro, aumentam-se as chances de obtenção de uma resposta veraz.

Tabela 11 - Já soube de algum colega que - para oferecer um atendimento diferenciado assumiu pessoalmente riscos maiores que o permitido pelos normativos da organização?

\begin{tabular}{lcc}
\hline & Frequência Relativa & Frequência Absoluta (\%) \\
\hline Sim & 29 & 60,4 \\
\hline Não & 19 & 39,6 \\
\hline Não se aplica às funções desempenhadas & 0 & 0,0 \\
\hline Total & 48 & 100,0
\end{tabular}

Fonte: elaborado pelos autores, com base nos dados da pesquisa.

Como se vê, 60,4\% dos respondentes disse conhecer colegas que já assumiram riscos maiores que os tolerados pela organização com o fito de oferecer ao(s) cliente(s) um atendimento diferenciado. Este número de respostas positivas apresentado na Tabela 11 é elevado e sinaliza que seis em cada dez bancários já testemunharam desobediência aos controles internos. O conflito de interesses com exposição a riscos, neste caso, é nítido.

As questões 10 e 11, que compõem e encerram esta seção 4.3, levam - portanto - à validação da premissa P3 ("Os funcionários toleram riscos não desejados pelo patrão em razão de ligações particulares com clientes?”). Deste modo, uma vez validadas as três 
premissas, conforme o rito estabelecido no quadro 1, pode-se dizer foi aceita a hipótese $\mathrm{H} 0$, a qual postulava que "o relacionamento interpessoal entre clientes e funcionários gera conflitos de interesses que afetam a implementação e o cumprimento das normas de controle interno".

\subsection{QUESTÕES AVALIADAS ATRAVÉS DE ESCALA LIKERT}

Para dar profundidade à analise dados e avaliar como a filosofia de negócios dialoga com as opções éticas dos funcionários, foram elaboradas algumas questões cujas alternativas de resposta foram gradativas e não taxativas, ou seja, os respondentes manifestaram o seu nível de concordância/discordância com a proposição formulada pelo pesquisador em vez de dar uma resposta monossilábica do tipo "sim" ou "não". Tal estratégia de investigação foi aplicada mediante uso da Escala Likert de cinco pontos, na qual o grau 1 representa a total discordância e o 5 a total concordância.

Assim, passando à Tabela 12, a seguir, é possível observar que $47 \%$ dos respondentes discordam de que a flexibilização da norma para clientes antigos expresse confiança. A ideia de fazer uma pergunta neste sentido - e desta forma - teve o intuito de avaliar se, de acordo com a compreensão dos bancários, o fator tempo de relacionamento com o banco induziria a uma compreensão mais laxa segundo a qual exceções à norma poderiam ser abertas em nome da confiança depositada no cliente.

Tabela 12 - Quando se trata de cliente(s) antigo(s), flexibilizar uma norma é um indicativo de confiança.

\begin{tabular}{lcc}
\hline & Frequência Relativa & Frequência Absoluta (\%) \\
\hline Discordo totalmente & 22 & 47,8 \\
\hline Discordo parcialmente & 6 & 13,0 \\
\hline Não concordo nem discordo & 5 & 10,9 \\
\hline Concordo parcialmente & 11 & 23,9 \\
\hline Concordo totalmente & 2 & 4,3 \\
\hline Total & 46 & 100,0 \\
\hline
\end{tabular}

Fonte: elaborado pelos autores, com base nos dados da pesquisa.

O resultado obtido acima reflete, talvez, um dilema ético que tem sido vivido pelos bancários atualmente: obedecer às exigências normativas (para não arriscar seu emprego) ao mesmo tempo em que reconhece que o trato devido a um cliente de longa data não é o mesmo dado a um cliente recente. Note-se que, embora em uma questão de princípios se esperem resultados mais "partidários", dicotômicos, 24 respondentes não acompanharam os 22 que disseram discordar totalmente da afirmação proposta.

Continuando a discussão sobre a flexibilização da norma para clientes antigos, foi perguntado aos bancários das agências que participaram da pesquisa se esta flexibilidade era vista como uma delicadeza, um gesto de amabilidade com o cliente. O percentual de discordância, neste caso, foi maior: $58,7 \%$ dos respondentes não encaram as coisas desta forma.

Tabela 13 - Quando se trata de cliente(s) antigo(s), flexibilizar uma norma é uma delicadeza.

\begin{tabular}{lcc}
\hline & Frequência Relativa & Frequência Absoluta (\%) \\
\hline Discordo totalmente & 27 & 58,7 \\
\hline Discordo parcialmente & 7 & 15,2 \\
\hline Não concordo nem discordo & 6 & 13,0 \\
\hline Concordo parcialmente & 5 & 10,9 \\
\hline Concordo totalmente & 1 & 2,2 \\
\hline Total & 46 & 100,0 \\
\hline
\end{tabular}

Fonte: elaborado pelos autores, com base nos dados da pesquisa.

GєCont, v. 5, n. 1, Floriano-PI, Jan-Jun. 2018. 
É preciso perceber o diferencial desta questão em relação à anterior: a introdução do elemento "delicadeza" teve por finalidade verificar em que medida ligações históricas com os clientes motivam a concessão de favores. Criar exceções à norma como se fossem cortesia para certo grupo de clientes (os antigos) indiciaria que a relação entre banco e clientes não estaria pautada apenas no cumprimento de deveres e exercício de direitos, mas sim em 'pactos de cavalheiros' - mesmo que destoantes das regras vigentes. Como quase sessenta por cento dos bancários discordou do enunciado proposto na questão 13, pode-se dizer que a maioria dos respondentes tem consciência clara de que flexibilizar a norma não é um préstimo a mais que se pode oferecer ao cliente.

Para mensurar o grau de dissociação entre amizade e negócios, foi proposto que os respondentes informassem o quanto concordavam com o ditado popular "Amigos, amigos. Negócios à parte". $51,1 \%$ das respostas colhidas foram "concordo totalmente". Na compreensão destes, o profissionalismo deve sobrepor a amizade e a ética deve suplantar as relações pessoais que porventura tenham sido construídas ao longo dos anos. Contudo, ainda surpreende que o público respondente esteja tão dividido com relação a esta questão. Somados os percentuais das outras opções fornecidas pela Escala Likert que foi aplicada, vêse que 48,9\% não dá seu total assentimento a esta afirmativa proposta na questão 14. A partir disto, é possível supor - com razoabilidade - que os bancários têm dificuldades em separar estas duas realidades (a pessoal e a profissional).

Tabela 14 - Quando se trata de cliente(s) antigo(s), deve prevalecer a máxima "Amigos, amigos. Negócios à parte"

\begin{tabular}{lcc}
\hline & Frequência Relativa & Frequência Absoluta (\%) \\
\hline Discordo totalmente & 7 & 15,6 \\
\hline Discordo parcialmente & 2 & 4,4 \\
\hline Não concordo nem discordo & 3 & 6,7 \\
\hline Concordo parcialmente & 10 & 22,2 \\
\hline Concordo totalmente & 23 & 51,1 \\
\hline Total & 45 & 100,0
\end{tabular}

Fonte: elaborado pelos autores, com base nos dados da pesquisa.

Saindo da seara dos "clientes antigos", a pergunta de número 15 abordou a questão da fidelidade ao banco. A suposição que embasou a arguição era a de que bancários poderiam querer recompensar tal fidelidade realizando concessões e flexibilizações não autorizadas pelos normativos da instituição financeira a que estão ligados. Os resultados encontrados foram bastante heterogêneos, de modo que apenas por agrupamento de opções se pôde chegar a algum entendimento: somando as opções que representam discordância ("discordo totalmente" e "discordo parcialmente"), vê-se que 55,6\% dos respondentes não acha que "cliente(s) fidelizado(s) ao banco merece(m) um tratamento normativo diferenciado". Esta sutil maioria ratifica o que todas as Tabelas desta seção 4.4 até agora apresentaram: embora os bancários se dividam quando a matéria é o juízo de questões éticas ligadas ao seu dia a dia, ainda prevalece (com um percentual suavemente mais elevado) o grupo que rechaça os vários tipos "favoritismos" que as questões sugerem e que, portanto, parece ter os seus valores éticos preservados. 
Tabela 15 - Cliente (s) fidelizado (s) ao banco merece (m) um tratamento normativo diferenciado

\begin{tabular}{lcc}
\hline & Frequência Relativa & Frequência Absoluta (\%) \\
\hline Discordo totalmente & 12 & 26,7 \\
\hline Discordo parcialmente & 13 & 28,9 \\
\hline Não concordo nem discordo & 3 & 6,7 \\
\hline Concordo parcialmente & 14 & 31,1 \\
\hline Concordo totalmente & 3 & 6,7 \\
\hline Total & 45 & 100,0 \\
\hline
\end{tabular}

Fonte: elaborado pelos autores, com base nos dados da pesquisa.

Na Tabela 16, tem-se outro prisma de análise: a lógica da reciprocidade. Este conceito, muito comum no meio bancário, foi introduzido na formação dos bancários pelas próprias instituições financeiras. O pressuposto é: quem quer algo do banco tem que dar algo ao banco e vice-versa. Por trás desta mentalidade está a ideia de que para perpetuar uma relação comercial é preciso intensificá-la - mediante aquisição de produtos e/ou contratação de serviços.

Tabela 16 - Cliente (s) que costuma (m) adquirir muitos produtos do banco merece (m) um tratamento normativo diferenciado

\begin{tabular}{lcc}
\hline & Frequência Relativa & Frequência Absoluta (\%) \\
\hline Discordo totalmente & 14 & 31,1 \\
\hline Discordo parcialmente & 9 & 20,0 \\
\hline Não concordo nem discordo & 3 & 6,7 \\
\hline Concordo parcialmente & 16 & 35,6 \\
\hline Concordo totalmente & 3 & 6,7 \\
\hline Total & 45 & 100,0
\end{tabular}

Fonte: elaborado pelos autores, com base nos dados da pesquisa.

Lemgruber e De Macedo Wellisch (1980) já haviam estudado o impacto da exigência de reciprocidade sobre algumas decisões tomadas por instituições financeiras, mas não chegaram a analisar se a raiz desta exigência (tida como prática ou costume) está associada a um "toma-lá-dá-cá" que desemboca em descumprimento dos controles internos.

É este exatamente o ponto da questão 16: se o cliente, cedendo à pressão por reciprocidade, contrata uma porção de produtos e serviços financeiros, ficará ele com 'cartas na manga' perante o banco? A receita que ele gera para o banco faz com que os bancários o considerem um ente acima da norma e, por isso, imune a ela? O resultado que ele proporciona à instituição faz com que os funcionários fechem os olhos certas irregularidades por ele cometidas?

Com números mais uma vez bastante controversos, os dados nos permitem dizer que $35,6 \%$ dos respondentes concordam parcialmente que clientes com alta reciprocidade (ou seja: os que costumam adquirir muitos produtos) merecem, sim, um "tratamento normativo diferenciado". Quando tabulados os dados (vide Tabela 16), este foi o percentual mais elevado que se obteve, com 16 pessoas assinalando a alternativa "concordo parcialmente". Saliente-se, porém, que 14 pessoas $(31,1 \%)$ marcaram a alternativa "discordo totalmente".

Continuando neste assunto concernente à reciprocidade, a questão 17 introduz uma possibilidade mais ousada: ela interroga sobre a utilização da norma flexível como moeda de troca para pedir aos clientes reciprocidade (leia-se: pedir que adquiram mais produtos ou serviços). Em sua maioria (43,5\%), os bancários respondentes discordam totalmente de que esta prática deva ocorrer. Contudo, ressalte-se que quase vinte por cento manifestaram apenas discordância parcial neste quesito. 
Tabela 17 - A flexibilização de uma norma pode ser realizada a fim de ter argumentos para solicitar ao (s) cliente (s) reciprocidade

\begin{tabular}{lcc}
\hline & Frequência Relativa & Frequência Absoluta (\%) \\
\hline Discordo totalmente & 20 & 43,5 \\
\hline Discordo parcialmente & 9 & 19,6 \\
\hline Não concordo nem discordo & 5 & 10,9 \\
\hline Concordo parcialmente & 10 & 21,7 \\
\hline Concordo totalmente & 2 & 4,3 \\
\hline Total & 46 & 100,0 \\
\hline
\end{tabular}

Fonte: elaborado pelos autores, com base nos dados da pesquisa.

$\mathrm{Na}$ última interrogação do questionário aplicado nesta pesquisa a temática foi os idosos, as pessoas com deficiência, e quaisquer outros grupos vulneráveis. A legislação em vigor já assegura a estas pessoas tratamento prioritário e facilitação do acesso delas às agências bancárias. Entretanto a natureza jurídica das relações negociais firmadas com estes clientes não difere daquilo que é pactuado com demais clientes. Ou seja: não existem contratos de exceção nem o banco constrói normativos específicos para estas pessoas.

Entretanto, dadas as particularidades deste público, pode ocorrer de funcionários de agências bancárias quererem flexibilizar normas para oferecer um atendimento diferenciado. Foi o que se tentou sondar com a questão 18, cujos resultados estão abaixo tabelados:

Tabela 18 - Deve-se flexibilizar a norma para atender a idosos, pessoas com deficiência, e quaisquer outras pessoas que apresentem algum tipo de vulnerabilidade

\begin{tabular}{lcc}
\hline & Frequência Relativa & Frequência Absoluta (\%) \\
\hline Discordo totalmente & 17 & 37,8 \\
\hline Discordo parcialmente & 12 & 26,7 \\
\hline Não concordo nem discordo & 1 & 2,2 \\
\hline Concordo parcialmente & 10 & 22,2 \\
\hline Concordo totalmente & 5 & 11,1 \\
\hline Total & 45 & 100,0 \\
\hline
\end{tabular}

Fonte: elaborado pelos autores, com base nos dados da pesquisa.

Dos bancários que responderam ao questionário desta pesquisa, a maior parte discordou da afirmação proposta (37,8\% discordaram totalmente e $26,7 \%$ discordaram parcialmente). Neste quesito, portanto, os interesses do banco parecem se harmonizar com o dos funcionários.

\section{CONSIDERAÇÕES FINAIS}

Este estudo teve o intuito de investigar se a existência de ligações pessoais entre clientes e funcionários de instituições financeiras seria capaz de fazer com que estes últimos infringissem as normas de compliance a que se submeteram por força de vínculo empregatício. A motivação para tal infração, segundo a hipótese formulada por esta pesquisa, estaria relacionada a conflitos de interesses entre o funcionário (que tenderia a preservar seu relacionamento pessoal com os clientes) e o banco (cuja preocupação seria minimizar riscos e evitar prejuízos).

Tendo validado todas as premissas estabelecidas, os dados obtidos a partir desta pesquisa confirmam a hipótese e permitem afirmar que clientes e funcionários das agências bancárias estudadas, de fato, mantêm relações que vão além da dimensão profissional, e que estas conexões pessoais ocasionam inobservância e desobediência aos controles internos. Embora as respostas a alguns quesitos tenham sido bastante heterogêneas, as questões avaliadas pela Escala Likert sugerem que - de um modo geral - a consciência ética e a noção

GєCont, v. 5, n. 1, Floriano-PI, Jan-Jun. 2018. 
de acerca do que é ou não adequado e justo estão preservadas na maioria dos respondentes. Isto indica que, quando violam os controles internos, estes funcionários o fazem cientes dos riscos inerentes a tal ato

Como já dito na metodologia, o questionário utilizado como ferramenta de coleta de dados para o presente estudo foi aplicado aos funcionários de apenas dez agências bancárias de Pernambuco. Isto constitui uma limitação da pesquisa e inviabiliza qualquer generalização dos resultados obtidos. A título de sugestão, recomenda-se ampliar a população de respondentes, agregando outras instituições financeiras e sondando funcionários de outros estados e localidades. É possível que, diante de elementos regionais e culturais diferentes, encontre-se maior (ou menor) exposição a riscos e conflitos de interesse, o que refletirá em maior ou menor adesão aos controles internos.

Os achados desta pesquisa oferecem um importante alerta para aqueles que gerenciam sucursais bancárias e/ou elaboram os controles internos de instituições financeiras. Com os resultados confirmando a acentuada vinculação pessoal entre clientes e funcionários, tem-se o subsídio necessário para iniciar uma discussão sobre reformulação de normas e procedimentos com vistas a prevenir uma exposição indesejada a riscos.

\section{REFERÊNCIAS}

ANTHONY, Robert N., GOVINDARAJAN, Vijayd. Sistemas de Controle Gerencial. São Paulo: Atlas, 2001. p. 32.

BIRINDELLI, Giuliana; FERRETTI, Paola. Compliance function in Italian banks: organizational issues. Journal of Financial Regulation and Compliance, v. 21, n. 3, p. 217 $240,2013$.

BOUÇAS, Angela Siebra; GOMES, Josir Simeone. Sistemas de Controle Gerencial em Empresas brasileiras internacionalizadas: o caso de uma empresa de material elétrico. Revista Universo Contábil, v. 6, n. 2, p. 06-26, 2010.

DELOACH, Jame W. Administração Corporativa de risco: estratégias para relacionar risco e oportunidade. New York: Pearson Education, 2001.

GITMAN, Lawrence J. Princípios de administração financeira. Harbra, 1997.

JACOMOSSI, Fellipe André et al. Gestão do risco estratégico em instituições bancárias: uma análise no período pós-crise subprime. Revista Grifos, v. 24, n. 38/39, p. 113-142, 2016.

JENSEN, Michael C.; MECKLING, William H. Theory of the firm: Managerial behavior, agency costs, and ownership structure. Springer Netherlands, 1976.

LARUCCIA, Mauro Maia; YAMADA, Karen Junko. O desenvolvimento sustentável e a gestão de compliance em instituições financeiras. Revista Estratégica, v. 11, n. 2, 2013.

LÉLIZ, Débora Lage Martins; MARIO, Poueri do Carmo. Auditoria interna com foco em governança, gestão de riscos e Controle interno: análise da auditoria interna de uma empresa do setor energético. In: Congresso USP de Controladoria e Contabilidade, 9 ${ }^{\circ} .2009$.

LEMGRUBER, Eduardo Facó; DE MACEDO WELLISCH, Ronaldo. Impacto da Reciprocidade Exigida por Instituições Financeiras nas Decisões de Gerência de Caixa da Firma. Revista de Administração da Universidade de São Paulo, v. 15, n. 4, 1980.

LIMA, Iran Siqueira; LOPES, Alexsandro Broedel. Contabilidade e controle de operações com derivativos. São Paulo: Pioneira, 1999. 
MARSHALL, Christopher. Medindo e Gerenciando Riscos Operacionais em Instituições Financeiras. São Paulo, Qualitymark Editora, 2002.

MERCHANT, Kenneth A.; SIMONS, Robert. Research and control in complex organizations: an overview. Division of Research, Graduate School of Business Administration, Harvard University, 1986.

SILVA, Juliana Lemos; NAVARRO, Vera Lucia. Organização do trabalho e saúde de trabalhadores bancários. Rev Latinoam Enferm2012, v. 20, p. 226-34, 2012. 